\title{
IMPORTÂNCIA PERCEBIDA E INTENÇÕES DE ENVOLVIMENTO COM A GESTÃO SOCIAL E A AMBIENTAL: UMA ANÁLISE COMPARATIVA JUNTO A ESTUDANTES DE CURSO DE ADMINISTRAÇÃO
}

\section{RESUMO}

Este estudo analisou a importância percebida e as intenções futuras em relação à gestão social e à ambiental, avaliando comparativamente as áreas. Foi feito um estudo de campo, com dados coletados com 403 estudantes de graduação em Administração das instituições de ensino superior do Nordeste do Brasil. Os dados foram analisados por meio de estatísticas descritivas (médias e frequências), análise fatorial exploratória (AFE) e análise de variância (ANOVA). Verificou-se que: (1) os estudantes atribuem uma maior importância no geral para a gestão ambiental do que para a social; (2) eles atribuem uma maior importância prática para a gestão ambiental; (3) quanto ao interesse futuro, a gestão ambiental despertou um maior envolvimento futuro do que a social. A análise de variância indicou que esses posicionamentos são influenciados, especialmente, pelo tipo de instituição e pela experiência na área na gestão ambiental, enquanto na gestão social são influenciados pelo gênero (homens e mulheres).

Palavras-chaves: Gestão ambiental. Gestão social. Cursos de Administração. Importância percebida. Intenções de envolvimento.

\section{ABSTRACT}

This study analyzed the perceived importance and future intentions with regards to social and environmental management, comparatively evaluating the areas. A field study with data collected from 403 Business Administration undergraduate students from institutions of higher education in the northeast of Brazil was done. The data were analyzed through descriptive statistics (averages and frequencies), exploratory factor analysis (EFA) and analysis of variance (ANOVA). It was found that: (1) students assign greater importance in general to the environmental over the social management; (2) they attribute a greater practical importance to the enviromental management; (3) as for the future interest, the environmental management evoked a greater future involvement than the social management. Analysis of variance indicated that these positions are influenced especially by the type of institution and by the experience in the area in environmental management, while in social management they are influenced by gender (men and women).

Keywords: Environmental management. Social management. Business Administration Courses. Perceived importance. Intent of involvement.
Ingrid Mazza

Faculdade Paraíso - CE

Mestrado em Administração pela

UECE

ingridmazza@gmail.com

Leonel Gois Lima Oliveira

Escola Brasileira de Administração Pública e de Empresas - Fundação Getúlio Vargas (EBAPE/FGV)

Doutorando em Administração leonelgois@gmail.com

Roberto Rodrigues Ramos Universidade Federal do Ceará (UFC)

Mestrado em Adminsitração pela UECE

robertoramos1977@gmail.com

Francisco José da Costa
Universidade Federal da Paraíba
(UFPB)
DOutorado em Administração de
Empresas pela FGV
franze@franzecosta.com

Recebido em 13/agosto/2009 Aprovado em 16/outubro/2011 
Importância Percebida e Intenções de Envolvimento com a Gestão Social e a Ambiental: uma análise comparativa junto a estudantes de curso de administração

\section{INTRODUÇÃO}

O debate sobre as questões sociais e ambientais vem ganhando crescente visibilidade no contexto acadêmico e organizacional, não importando se a organização seja de natureza pública ou empresarial. Uma das razões para tal acontecimento parece ser a percepção - por parte da sociedade, em geral, e das organizações, em particular - da atual situação de intensa desigualdade social e de degradação ambiental. Isso está bem ilustrado no forte movimento da gestão social e da ambiental responsável e, mais recentemente, na preocupação do desenvolvimento de um modelo de gestão profissionalizado para as organizações.

Observa-se a construção de um discurso cada vez mais consolidado de que a adaptação das organizações a uma perspectiva de gerenciamento social é vista como um diferencial competitivo diante de seus stakeholders. Por outro lado, o desenvolvimento teórico e disciplinar da gestão social ainda parece incompleto e sem um caminho bem definido. França Filho (2008), por exemplo, aponta que a importância hoje dada para a questão social sugere duas tendências. A primeira diz respeito à banalização do tema, o que tem levado o assunto a ser mal interpretado e a não ter precisão conceitual. Além disso, a relevância atual do tema tem ligação com o crescimento da discussão sobre o papel das organizações privadas agindo sobre obrigações que primeiramente eram consideradas de responsabilidade das organizações públicas.

Ocupando posição similar à da gestão social, o debate sobre as questões ambientais vem ganhando crescente importância no contexto organizacional, público ou empresarial, em razão dos constantes alertas de cientistas e de organismos multilaterais sobre as consequências da má gestão ambiental, além da percepção dos gestores de que o tema será importante para a decisão dos consumidores. Com efeito, a preocupação ambiental atual representa uma mudança de paradigma quanto ao futuro do meio empresarial e da sociedade de uma maneira geral. Esty e Winston (2006) comentam que a "Onda Verde" atinge todos os tipos de empresas, e aquelas que estiverem melhor adaptadas obterão sucesso. Com um pensamento semelhante, Lash e Wellington (2007) ressaltam a importância de que as empresas que se prepararem o mais rápido possível certamente conseguirão destaque e obterão uma melhor vantagem competitiva.

A despeito dessa crescente conscientização, percebe-se que o campo da gestão ambiental ainda está em formação, com muitas lacunas e com ausência de práticas decisivas para uma mudança de paradigma. Jabbour, Santos e Barbieri (2008) realizam um levantamento da produção científica em gestão ambiental nos principais periódicos do Brasil e concluem que a produção corresponde a apenas 2,3\% da produção total na área de administração. Além disso, essa mesma produção é restrita a um pequeno grupo de instituições e pesquisadores, visto que quase $60 \%$ da produção é restrita a cinco instituições. Verificase, também, a necessidade de maior disseminação do conhecimento sobre o tema, alinhado com as principais demandas atuais e futuras. Tal propósito requer uma forte concentração na identificação dessas demandas, especialmente em nível local.

Nesses termos, cabe às instituições de ensino a tarefa de protagonizar o desenvolvimento de projetos de educação e de gestão ambiental, como um meio viável para uma formação profissional consistente. Barbieri e Silva (2011) ressaltam que a educação ambiental é importante para profissionais cujas atividades e decisões repercutem significativamente sobre o meio ambiente, como engenheiros, economistas, administradores, desenvolvedores de produtos, entre outros. Assim, além da formação da consciência, requer-se, também, a formação de competências para a atuação em um contexto complexo e multidisciplinar (RIGONAT, 2002).

Nascimento (2007) sugere a utilização do termo gestão socioambiental, referindo uma aproximação recente dos modelos conceituais da gestão social e da ambiental, apesar de demonstrar que os citados conceitos surgiram de pontos distantes. Mesmo assim, a percepção da diferenciação por parte das pessoas entre as duas áreas é algo questionável e, segundo Silva Filho (2007, exige cuidados para evitar uma diluição entre dois conceitos.

Assim, considerando a proeminência da temática 
Importância Percebida e Intenções de Envolvimento com a Gestão Social e a Ambiental: uma análise comparativa junto a estudantes de curso de administração

para a formação em Administração, definiu-se como objetivo desta pesquisa avaliar a importância da gestão ambiental e da gestão social para a formação profissional sob a ótica de estudantes de Administração e, com base nisso, realizar análises comparativas das duas áreas de estudo. Analisaram-se, também, as intenções futuras desses alunos em relação a essas áreas, evidenciando a existência, ou não, de percepções diferenciadas de um mesmo público por meio de comparações dos resultados.

O trabalho, portanto, reúne informações para que gestores de cursos e de instituições que oferecem cursos na área de Administração tomem decisões mais consistentes no que diz respeito a projetos de formação de gestores para esses campos, visto que a temática tende a apresentar uma maior demanda por parte dos administradores profissionais no futuro.

Afora esta introdução, o restante do artigo está esquematizado em mais quatro seções. A segunda seção descreve os fundamentos teóricos do tema. Em seguida é especificado o caminho metodológico adotado para o alcance dos dados. Na quarta seção expõem-se as análises da pesquisa de campo realizada e os resultados, com os dados comparativos. No último item são feitas as considerações e recomendações finais.

\section{REVISÃO TEÓRICA}

Aqui são apresentados os fundamentos teóricos do trabalho. Considerou-se apropriado dividir o item em duas partes: debate-se, inicialmente, acerca da gestão social em seu contexto geral e a formação na área, e na sequência faz-se o mesmo em relação à gestão ambiental.

\subsection{Gestão Social: Contexto geral}

A gestão social ainda é uma área acadêmica em formação e, por esse motivo, alguns conceitos, ações e práticas estão em busca de uma melhor consolidação tanto no campo acadêmico quanto no de mercado. Pela revisão de literatura, percebe-se que a exata delimitação conceitual para a própria expressão 'gestão social' ainda é um desafio.

França Filho (2008), por exemplo, observa que o termo tem se referido à identificação de diferentes práticas sociais, oriundas de organizações governamentais, e principalmente não governamentais, além de algumas iniciativas do setor privado, especialmente quando estas últimas pautam suas ações nas noções de cidadania corporativa e de responsabilidade social empresarial (aliás, termos que também surgiram recentemente no debate em Administração (SILVA FILHO, 2007)). Silva Jr. et al. (2008) corroboram essa ideia quando afirmam que a gestão social está relacionada à gestão de organizações e suas relações com os diferentes atores sociais (primeiro, segundo e terceiro setor).

No entendimento de Tenório (2008), gestão social é tida como um processo gerencial, que tem caráter decisório e deliberativo, e visa suprir demandas de uma sociedade específica, no que diz respeito à produção de bens e à prestação de serviços. Visto por esse ângulo, já pode ser observada de forma mais clara a vinculação do tema com o contexto empresarial. Porém a gestão social difere da gestão empresarial propriamente dita, já que esta última mantém foco na competitividade, no lucro e na exclusão dos concorrentes, enquanto a primeira é baseada na solidariedade, na cooperação e na inclusão do próximo (TENÓRIO, 2004).

França Filho (2008), apesar de afirmar que todas as formas de gestão são sociais, considera ser importante levar em conta dois níveis de análise da gestão social: a que a identifica com uma problemática da sociedade (nível societário), e a que a relaciona com uma forma particular de gestão (nível organizacional). No primeiro nível, o conceito confunde-se com a própria ideia de gestão pública, ainda que as demandas sociais possam também ser geridas, de certa forma, pela sociedade como um todo, com base em seus mecanismos de auto-organização.

No segundo nível, o autor afirma que a gestão social diz respeito a uma forma de gestão organizacional, diferente da gestão privada (atua no mercado) e da pública (atua nas instituições do Estado), que visa diminuir a lógica instrumental e técnica para uma visão mais social, política, cultural e ecológica no escopo da gestão (FRANÇA FILHO, 2008). Essa proposta ilustra uma tentativa de demarcação que envolve tanto o nível organizacional quanto o governamental, ainda que o 
Importância Percebida e Intenções de Envolvimento com a Gestão Social e a Ambiental: uma análise comparativa junto a estudantes de curso de administração

próprio autor se detenha mais no segundo nível.

Por essa linha de pensamento, a gestão social é a forma de gestão própria das organizações que atuam em um contexto que não é, em sua origem, nem o de mercado, nem o do Estado. É nessa lacuna que se encontra a sociedade civil, em que as práticas são de esfera pública, mas não provêm de organizações estatais. Contudo, as organizações da sociedade civil também não visam o lucro e se utilizam das finanças apenas como um meio para alcance dos fins sociais predeterminados. Esses fins podem ser de cunho cultural, político, ecológico, educacional, entre outros, dependendo do campo de atuação da organização da sociedade civil (SCHOMMER; FRANÇA FILHO, 2008).

Considerou-se, para a presente pesquisa, gestão social como: (1) a atividade de gestão associada às organizações não empresariais e não estatais, tais como cooperativas, associações, ONGs, e outras semelhantes; (2) a gestão das organizações e de suas relações com as mais variadas práticas sociais de diferentesatores(governamentais, não-governamentais e do setor privado), associando objetivos não apenas econômicos, mas, também, sociais, políticos, culturais e ecológicos (FRANÇA FILHO, 2008).

É possível observar, no universo empresarial, a tentativa de se responder aos anseios sociais de toda a sociedade, desde seus funcionários até seus consumidores, estabelecendo regras particulares, como forma de guiar as organizações em suas ações. Em nível nacional, destaca-se o posicionamento de inúmeras empresas que têm buscado melhores práticas, desde a produção até a comunicação de seus produtos e serviços, e ainda o trabalho do Instituto Akatu, que acompanha e dissemina muitas dessas ações (INSTITUTO AKATU, 2009).

SchommereFrançaFilho(2008)afirmam quejunto com o uso da expressão gestão social, em diferentes contextos, aumenta também o empenho acadêmico e o de outras organizações voltadas ao ensino e à pesquisa, no sentido de sistematizar conhecimentos e informações para estabelecer uma estrutura de conceitos, metodologias e ferramentas que ofereçam sustentação para toda a sociedade, no que diz respeito à gestão social. Sendo assim, é papel das instituições de ensino tomar a frente no desenvolvimento de projetos educacionais de gestão social como uma forma possível de formar profissionais preparados para atender às demandas sociais.

Mediante o que foi relatado, é possível visualizar a importância da formação em gestão social para estudantes de cursos de Administração, de forma que esses futuros profissionais venham, em primeiro lugar, estar cientes do novo contexto de gestão que estará presente em sua futura carreira e, em segundo lugar, exercer o trabalho de gestão de organizações sociais.

\subsection{Gestão Ambiental: Contexto geral}

Seguindo a mesma tendência da gestão social, a gestão ambiental ainda é um campo em formação e, por essa razão, alguns conceitos, ações e práticas estão à procura de uma melhor consolidação teórica e pragmática (JABBOUR; SANTOS; BARBIERI, 2008). Conforme consta em Silva, Silva e Enders (2006), um conceito consistente de gestão ambiental é aquele que a entende como uma estrutura gerencial a qual permite que a organização visualize os impactos de suas ações no meio ambiente. Para tanto, a organização deve desenvolver um sistema que permita e facilite o acesso, a catalogação e a quantificação dos impactos ambientais das operações de toda ela.

Em uma avaliação do entendimento de Silva, Silva e Enders (2006), fica evidente uma vinculação do conceito de gestão ambiental ao contexto organizacional, ou seja, a proposta relaciona-se mais ao impacto das ações organizacionais (principalmente empresariais), do que na composição de esforços para atingir esses mesmos objetivos. A gestão ambiental seria, portanto, antes um conjunto de ações para minimizar o impacto das ações potencialmente agressivas ao meio ambiente do que um conjunto de ações para contribuir para o alcance dos objetivos em si. Já para Melo Neto e Brennand (2004), a gestão ambiental representa o último estágio de atuação da empresa em relação à problemática do meio ambiente.

Ademais, tem-se que a gestão ambiental no plano organizacional difere do conceito no plano governamental, posto que os governos desenvolvem ações com a finalidade restrita ao meio ambiente 
em si. A utilização da mesma expressão para os dois contextos (organizacional e governamental) traz a possibilidade de confusão conceitual. A exata delimitação que pondera os dois contextos constitui um desafio para a literatura.

Avaliando a necessidade de uma melhor delimitação do campo, Barbieri (2004) observou que qualquer proposta de gestão ambiental inclui, no mínimo, três dimensões, a saber: (1) a dimensão espacial, que concerne à área na qual se espera que as ações de gestão ambiental tenham eficácia; (2) a dimensão temática, que delimita as questões ambientais às quais as ações se destinam; e (3) a dimensão institucional, relativa aos agentes que tomam iniciativas de gestão.

A proposta de Barbieri (2004) ilustra uma tentativa de delimitação que envolve tanto o nível organizacional quanto o governamental, ainda que a proposta atenda melhor ao segundo contexto. Por outro lado, acredita-se que as ações dos governos ganham maior consistência e os resultados passam a ser melhores mediante o envolvimento da sociedade civil e do universo empresarial. Daí provém a relevância da formação em gestão ambiental para estudantes de cursos de Administração, seja com orientação para empresas ou para quaisquer outros tipos de organização.

É possível observar, no universo empresarial, a tentativa de se responder aos anseios sociais, estabelecendo regras particulares como forma de guiar as organizações em suas ações ambientais. No plano internacional destaca-se o posicionamento da Associação Espanhola de Contabilidade e Administração de Empresas, que estabeleceu regras para o comportamento e a atuação das empresas em suas funções econômicas. No Brasil, destacase o posicionamento do Instituto Ethos, que propõe diretrizes e dá o devido reconhecimento para empresas que mantêm compromisso com o meio ambiente (INSTITUTO ETHOS, 2005a, 2005b).

Quanto ao gerenciamento ambiental, merece destaque a existência de uma norma internacional sobre o tema, a norma ISO 14001, elaborada pela International Organization for Standardization (ISO), fundada no ano de 1947, e localizada em Genebra, na
Suíça. Ressalta-se, nesse caso, que essa é uma norma de gerenciamento, e não se uma norma de desempenho ou de produto. Seu propósito é focalizar o processo de gerenciamento das atividades da organização que possuem impacto no ambiente (NASCIMENTO; LEMOS; MELLO, 2008). Ademais, os requisitos da norma são baseados nos seguintes aspectos: exigências gerais; política ambiental; planejamento; execução e operação; verificação e ação corretiva; revisão da administração (ABNT, 2004).

Complementarmente, em nível de formação, verificou-se na literatura a existência de trabalhos que abordam a temática relacionada à gestão ambiental, buscando a educação com o trabalho com crianças até o nível universitário ou mesmo profissional. (REIGOTA, 1994; CAPRA, 2007; NASCIMENTO; LEMOS; MELLO, 2008; BARBIERI; SILVA, 2011).

No Brasil, a abordagem da temática ambiental foi, aliás, regulamentada pela Lei $\mathrm{N}^{\circ} 9.795$, de 27 de abril de 1999 (Política Nacional de Educação Ambiental no Brasil), que definiu a obrigatoriedade de se abordar o tema ambiental de forma transversal. Especificamente sobre a gestão ambiental, a Lei prevê que a política de educação ambiental deverá promover a preparação de profissionais orientados para as atividades de gestão ambiental (BRASIL, 2007).

Barbieri e Silva (2011) ressaltam que a Educação Ambiental deve ser trabalhada tanto com profissionais - cujas atividades e influências repercutem no meio ambiente (administradores, economistas, engenheiros, agricultores, entre outros) — como também com profissionais que valorizam os problemas ambientais específicos (por exemplo, geólogos, biólogos, meteorologistas, agrônomos). Com base nessas reflexões sobre a gestão social e a ambiental, uma questão que se coloca é sobre qual o lugar e a forma de preparação de profissionais para atuar nessas áreas.

Em uma primeira análise, é aceitável conceber que as escolas de Administração seriam os locais preferenciais para a formação desses profissionais, pois o trabalho de gestão é inerente à profissão. Além disso, tal formação também poderia se realizar na forma de cursos bem direcionados, seja no formato de habilitações ou na oferta de disciplinas específicas, seguindo as recomendações internacionais para 
Importância Percebida e Intenções de Envolvimento com a Gestão Social e a Ambiental: uma análise comparativa junto a estudantes de curso de administração

a promoção da educação ambiental (BARBIERI; SILVA, 2011). Na ótica dos professores sobre a área de gestão ambiental, um estudo realizado por Oliveira, Oliveira e Costa (2010), demonstra que os professores do curso de graduação em Administração de Fortaleza$\mathrm{CE}$ avaliam a temática como muito relevante para o curso, embora com uma necessidade moderada e um baixo envolvimento por parte deles.

Mesmo com esses estudos exploratórios, acredita-se ser ainda imperativo que os cursos de Administração, na sua modalidade clássica, se preocupem com a gestão ambiental e a gestão social, e até se esforcem para promover a formação de profissionais para atender as diversas demandas existentes. A questão que surge, nesse caso, é se os atuais estudantes percebem essas necessidades. Sendo assim, avaliar essa questão de forma comparativa é a finalidade central deste trabalho.

\section{METODOLOGIA}

A pesquisa foi desenvolvida em três etapas: procedimentos exploratórios; definição do instrumento e coleta de dados; trabalho empírico. Os procedimentos exploratórios foram desenvolvidos em duas fases. A primeira fase constou da pesquisa bibliográfica, exposta no item anterior. Já a segunda consistiu nos procedimentos exploratórios gerais.

Nesse caso, identificou-se, primeiramente, estudos empíricos com objetivos semelhantes aos propósitos deste estudo, especialmente para reconhecer possíveis escalas para mensuração. Diversos estudos foram encontrados em temas como ética e responsabilidade social, com poucos itens de literatura tratando especificamente sobre gestão ambiental.

Após esses procedimentos iniciais, foi selecionado como instrumento de coleta de dados o questionário, sendo um para gestão social e outro para gestão ambiental. Foi decidido que tal instrumento seria dividido em três blocos de questões: o primeiro deles conteria as variáveis de identificação relacionadas à formação e à experiência do estudante; o segundo envolveria as questões dos construtos do estudo (gestão social ou gestão ambiental); e, por fim, o terceiro bloco traria questões sobre dados demográficos e socioeconômicos.

Para a definição dos itens dos construtos, e visando a análise da relevância da gestão ambiental, foi especialmente importante o estudo de Sleeper et al. (2006), no qual foi desenvolvida uma escala para avaliação do 'papel da educação em negócios em relação aos temas sociais' (Escala BERSI - [B] usiness [E]ducation's [R]ole in addressing [S]ocial [I]ssues). Os dez itens dessa escala foram traduzidos, analisados e adaptados para o contexto das gestões ambiental e social. Além dos itens dessa escala, também foram definidos, tomando por base os tópicos da literatura pesquisada, quatro itens para avaliar a predisposição dos estudantes em manter envolvimento futuro com a gestão social e/ou com a ambiental.

Os dez itens sobre a percepção da relevância da gestão foram apresentados como afirmações, com averiguação do grau de concordância por meio de uma escala de Likert de 5 pontos, com extremos de 1 para 'discordância total', e 5 para a 'concordância total'. Já nos quatro itens sobre intenções futuras, questionavase a probabilidade de o respondente seguir a alternativa de envolvimento proposta, em uma escala de 5 pontos, com extremos de 1 para 'muito improvável', e 5 para 'muito provável'. Após a consolidação preliminar dos instrumentos, eles foram submetidos a um pré-teste com dez respondentes. Após os devidos ajustes, os questionários foram aplicados.

As decisões de aplicação foram as seguintes: o universo da pesquisa foi constituído por estudantes de cursos de graduação em Administração das instituições de ensino superior do Nordeste do Brasil. Segundo dados do Ministério da Educação (2009), o total de alunos matriculados nos cursos presenciais de administração foi de 604581 naquele ano para todo o País. Embora o número de alunos matriculados nesse curso não esteja disponível para o ano de 2011, acreditase que há uma aproximação desse total. Foi coletada, para esta pesquisa, uma amostra de 403 estudantes. A coleta de dados foi procedida pelos autores. Entre os meses de abril e maio de 2007 foram aplicados os 190 questionários de gestão ambiental. Os questionários de gestão social foram aplicados nos meses de janeiro e fevereiro do ano de 2009, no total de 213. O tempo médio de resposta foi de 10 minutos. 
Importância Percebida e Intenções de Envolvimento com a Gestão Social e a Ambiental: uma análise comparativa junto a estudantes de curso de administração

Após a consolidação da planilha para a análise dos resultados dos dados coletados, procedeu-se inicialmente à verificação de valores faltantes (missing values), assim como de existência de valores atípicos (outliers), especialmente nos itens dos construtos. Posteriormente, foram extraídas as estatísticas descritivas das variáveis categóricas (primeiro e terceiro blocos). Para as variáveis da escala BERSI, procedeu-se inicialmente à análise fatorial exploratória (AFE), com a finalidade de avaliar a estrutura e a adequação fatorial dos itens. Em seguida, foram extraídas as médias e os desvios-padrão das variáveis, e o comportamento fatorial da escala BERSI nas duas amostras e foi comparado, sendo feitas algumas considerações sobre a sua dimensionalidade e confiabilidade. Por fim, foram extraídas e comparadas as medidas da escala de intenções futuras nas duas pesquisas.

Adicionalmente, foi verificada a confiabilidade dos conjuntos de itens a começar do coeficiente Alpha de Cronbach. De posse desses resultados, foi procedida a redução do número de variáveis mediante agregação dos itens por fator, tendo-se adotado como procedimento a extração pela média das entradas das variáveis componentes. Esse procedimento, recomendado por Bagozzi e Edwards (1998), tem a vantagem de manter o resultado na escala da pesquisa (de 1 a 5), apesar de ter o problema da redução da dispersão, pela redução do tamanho do desviopadrão.

Todos os procedimentos estatísticos foram desenvolvidos com suporte nas recomendações de autores especialistas nas técnicas utilizadas
(MALHOTRA, 1999; HAIR et al., 2005), e foram realizados por meio do software SPSS, versão 15.

\section{ANÁLISE DE DADOS}

Para a avaliação e a comparação dos dados da pesquisa de campo na área de gestão social e na área ambiental, decidiu-se pela exposição em dois momentos distintos: inicialmente apresentam-se os resultados descritivos das amostras e, em seguida, os procedimentos da análise dos construtos da pesquisa.

\subsection{Descrições das Amostras}

Das 174 entradas consideradas após a limpeza da planilha de gestão ambiental, 37,9\% correspondem a alunos de instituições públicas e 62,1\% referem-se a alunos de instituições privadas. Quanto à distribuição por ano letivo, 19\% indicaram o primeiro ano, 37,4\% o segundo ano, 20,7\% estavam no terceiro ano, enquanto o restante dos alunos informou estar no quarto ou no quinto ano (22,9\% dos respondentes).

Já das 213 entradas consideradas para a área de gestão social, 56,3\% correspondem a alunos de instituições públicas e 43,7\% referem-se a alunos de instituições privadas. Quanto à distribuição por ano letivo, $18,6 \%$ indicaram estar cursando o primeiro ano, $21,9 \%$ o segundo ano, $24,3 \%$ cursavam o terceiro ano, $22,4 \%$ o quarto ano, enquanto o restante $(12,9 \%$ dos respondentes) informou estar no quinto ano. Quanto às variáveis sociodemográficas dos questionários de gestão ambiental e de social, os resultados podem ser visualizados na Tabela 1 .

Considerando a distribuição das frequências pelas diferentes categorias das variáveis apresentadas, é

Tabela 1 - Informações sobre a amostra de Gestão Ambiental e de Gestão Social

\begin{tabular}{|c|c|c|c|c|c|}
\hline \multicolumn{3}{|c|}{ Gênero } & \multicolumn{3}{|c|}{ Estado Civil } \\
\hline & Gestão & Gestão & & Gestão & Gestão \\
\hline & Social & Ambiental & & Social & Ambiental \\
\hline \multirow{3}{*}{$\begin{array}{l}\text { Masculino } \\
\text { Feminino }\end{array}$} & $531 \%$ & $466 \%$ & Solteiro & $85,4 \%$ & $85,1 \%$ \\
\hline & 4600 & $50,0 / 0$ & Casado & $10,8 \%$ & $11,5 \%$ \\
\hline & & $53,4 \%$ & Outro & $3,3 \%$ & $3,4 \%$ \\
\hline \multicolumn{3}{|c|}{ Idade } & \multicolumn{3}{|l|}{ Renda } \\
\hline & $\begin{array}{l}\text { Gestão } \\
\text { Social }\end{array}$ & $\begin{array}{c}\text { Gestão } \\
\text { Ambiental }\end{array}$ & & $\begin{array}{l}\text { Gestão } \\
\text { Social }\end{array}$ & $\begin{array}{c}\text { Gestão } \\
\text { Ambiental }\end{array}$ \\
\hline Até 21 anos & $338 \%$ & 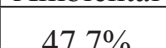 & Até R\$ 1000,00 & $8,0 \%$ & $29,2 \%$ \\
\hline Ate 21 anos & $\begin{array}{ll}35,8 \% \\
20\end{array}$ & $4 /, 1 \%$ & De $\mathrm{R} \$ 1000,00$ até $\mathrm{R} \$ 2000,00$ & $17,8 \%$ & $17,9 \%$ \\
\hline Acima de 21 até 24 anos & $28,2 \%$ & $27,6 \%$ & De $R \$ 2000,00$ até $R \$ 3000,00$ & $21,6 \%$ & $17,9 \%$ \\
\hline Acima de 24 anos & $38,0 \%$ & $24,7 \%$ & Acima de R $\$ 3000,00$ & $52,6 \%$ & $35,0 \%$ \\
\hline
\end{tabular}

Fonte: dados da pesquisa. 
possível assegurar que a amostra apresentou um bom equilíbrio, correspondendo bem à realidade (exploratoriamente) verificada, o que viabiliza condições consistentes para as análises posteriores.

Com relação à ocorrência de trabalhar ou de ter trabalhado com atividades associadas à gestão ambiental, apenas $11,5 \%$ afirmaram já possuir tal experiência, enquanto a grande maioria $(88,5 \%)$ afirmou não possuir qualquer experiência na área. Daqueles que responderam positivamente, cinco indicaram o envolvimento da gestão ambiental no próprio trabalho, sete afirmaram o envolvimento em projetos na faculdade, seis indicaram atividades em organizações não governamentais (ONGs), e um indicou trabalhar em empresa especializada na área ambiental.

Os resultados dos respondentes de gestão social sobre a questão de envolvimento revelam que apenas 22,1\% afirmaram já possuir experiência na área, enquanto a grande maioria $(77,9 \%)$ afirmou não possuir nenhuma experiência na área. Daqueles que responderam positivamente, nove indicaram o envolvimento da gestão social no próprio trabalho, cinco afirmaram o envolvimento em projetos na faculdade, 20 indicaram atividades em organizações não governamentais (ONGs), e dois indicaram trabalhar em empresa especializada na área de gestão social.

Quando indagados sobre onde, academicamente, a temática da gestão ambiental deveria ser abordada, $2,3 \%$ dos respondentes disseram que deveria ser em nível de pós-graduação, enquanto a maioria $(48,3 \%)$ entendeu que o assunto deveria ser uma disciplina de graduação. Por fim, um total de 40,2\% afirmou que o tema deveria ser abordado como Projeto Multidisciplinar ou como Atividades Complementares. Esses últimos percentuais são indicativos de que uma disciplina no curso ou projetos acadêmicos satisfaria o interesse da grande maioria dos estudantes. Foi pequeno, ainda, o percentual de alunos que entenderam que a gestão ambiental deveria ser trabalhada em um curso específico (6,9\%), além de apenas 2,3\% indicarem 'outros' como alternativa.
Já os respondentes de gestão social interpretaram da seguinte forma o lugar acadêmico da área: a maioria (49,3\%) entendeu que o assunto deveria ser uma disciplina do currículo da graduação, e um total de $41,3 \%$ afirmou que o tema deveria ser abordado como projeto multidisciplinar ou como atividades complementares (o restante apontou 'outros' como resposta). Esses percentuais são indicativos de que uma disciplina no curso ou projetos acadêmicos satisfaria o interesse da grande maioria dos estudantes.

\subsection{Análise dos Construtos na Gestão Social}

Como foi esclarecido na metodologia, este trabalho utilizou-se de uma escala já consolidada (BERSI) e adaptada para o contexto da pesquisa, além de ter proposto a mensuração das 'intenções futuras' de envolvimento dos estudantes com as duas áreas, por meio de quatro itens, criados com base na literatura pesquisada. Nesta seção, serão apresentados os resultados descritivos e psicométricos da Escala BERSI e dos itens relativos às 'intenções futuras', ambas em relação à gestão social.

\subsubsection{Análises dos construtos da escala BERSI na Gestão Social}

$\mathrm{Na}$ análise do bloco de variáveis da escala BERSI na pesquisa a respeito da gestão social, optou-se inicialmente por reunir as dez variáveis em um procedimento de análise fatorial exploratória. Assim, utilizando o método de estimação da análise de componentes principais, com rotação varimax, observou-se que dois fatores emergiram nos resultados de gestão social, com variância extraída de 57,4\% (46,4\% no primeiro fator, e $10,9 \%$ no segundo). A Tabela 2 (coluna Fatores) indica os valores dos escores fatoriais por variável nos dois fatores.

Como é possível verificar, os dois fatores são bem diferenciados, ficando cada um com cinco variáveis, cada uma delas com escore fatorial mínimo acima de 0,5. A análise dos sentidos dos enunciados das variáveis deixa evidente que o primeiro fator realça as variáveis associadas à 'importância da formação na área' de gestão social, ao passo que o segundo fator é formado por variáveis de sentido associado à ‘importância conhecimento prático’ em gestão social. 
Importância Percebida e Intenções de Envolvimento com a Gestão Social e a Ambiental: uma análise comparativa junto a estudantes de curso de administração

Tabela 2 - Medidas das variáveis da escala BERSI para Gestão Social

\begin{tabular}{|c|c|c|c|c|}
\hline \multirow[b]{2}{*}{ VARIÁVEIS } & \multicolumn{2}{|c|}{ FATORES ${ }^{1}$} & \multirow{2}{*}{ Média } & \multirow{2}{*}{ Desvio } \\
\hline & Fator $1^{2}$ & Fator $2^{3}$ & & \\
\hline $\begin{array}{l}\text { Cursos de Administração deveriam avaliar nos alunos conhecimentos sobre } \\
\text { gestão social }\end{array}$ & 0,841 & - & 3,64 & 1,01 \\
\hline $\begin{array}{l}\text { Cursos de Administração deveriam incluir tópicos, nas várias disciplinas, } \\
\text { sobre gestão social }\end{array}$ & 0,599 & - & 4,01 & 0,95 \\
\hline Uma boa formação em Administração passa pela formação em gestão social & 0,688 & - & 3,83 & 0,98 \\
\hline $\begin{array}{l}\text { Cursos de Administração deveriam incluir no currículo conteúdos/ } \\
\text { disciplinas sobre gestão social }\end{array}$ & 0,742 & - & 4,10 & 1,00 \\
\hline $\begin{array}{l}\text { Cursos de Administração deveriam preparar estudantes para serem líderes } \\
\text { de projetos sociais }\end{array}$ & 0,593 & - & 3,80 & 0,94 \\
\hline $\begin{array}{l}\text { Cursos de Administração deveriam envolver os estudantes em assuntos } \\
\text { sociais }\end{array}$ & - & 0,615 & 4,13 & 0,94 \\
\hline $\begin{array}{l}\mathrm{O} \text { aprendizado sobre gestão social é um assunto de grande importância para } \\
\text { a formação em Administração }\end{array}$ & - & 0,525 & 4,14 & 0,87 \\
\hline $\begin{array}{l}\text { Escolas de Administração deveriam oferecer oportunidades para que os } \\
\text { estudantes aumentem sua compreensão sobre gestão social }\end{array}$ & - & 0,785 & 4,42 & 0,86 \\
\hline $\begin{array}{l}\text { Escolas de Administração deveriam incentivar estudantes para se } \\
\text { envolverem em projetos sociais }\end{array}$ & - & 0,809 & 4,36 & 0,97 \\
\hline $\begin{array}{l}\text { Graduandos em Administração devem saber como resolver problemas de } \\
\text { gestão social }\end{array}$ & - & 0,731 & 4,30 & 0,84 \\
\hline
\end{tabular}

${ }^{1}$ Expostos somente valores de escores acima de 0,$5 ;{ }^{2}$ Variância extraída - 46,4\%; Alpha (de Cronbach) - 0,81; ${ }^{3}$ Variância extraída - 11,0\%, Alpha-0,79;

Fonte: dados da pesquisa.

Como é possível observar pelas médias gerais, nas variáveis do fator 'importância da formação na área' de gestão social as médias dos itens oscilaram bastante, sendo três delas menores que quatro, e duas com médias pouco acima desse valor. Tendo em vista que a escala foi de 1 a 5 , é possível entender que os estudantes, em geral, percebem uma necessidade entre moderada e elevada. Com relação aos desvios-padrão das cinco variáveis desse primeiro fator, observase que todos ficaram muito próximos de um, o que indica uma dispersão moderada nas percepções dos estudantes.

Já em relação às médias gerais das variáveis do fator 'importância do conhecimento prático' em gestão social, observaramse médias mais elevadas, e todas acima de quatro, dando,

Tabela 3 - Medidas das variáveis de intenções futuras em relação à Gestão Social

\begin{tabular}{|c|c|c|c|}
\hline VARIÁVEIS & FATOR $^{1}$ & MÉDIA & DESVIO \\
\hline Probabilidade de fazer cursos diversos na área de gestão social & 0,829 & 3,23 & 0,80 \\
\hline Probabilidade de me envolver em projetos sociais & 0,546 & 3,73 & 0,85 \\
\hline Probabilidade de fazer uma pós-graduação em gestão social & 0,824 & 2,61 & 0,96 \\
\hline Probabilidade de trabalhar como gestor social & 0,844 & 2,96 & 0,96 \\
\hline
\end{tabular}

${ }^{1}$ Variância extraída - 59,4\%, Alpha (de Cronbach) - 0,76

Fonte: dados da pesquisa prática na área relevante e são bastante convergentes quanto a essa opinião.

\subsubsection{Análises das 'intenções futuras'de envolvimento com a Gestão Social}

$\mathrm{Na}$ análise dos itens referentes às 'intenções futuras' de envolvimento, na pesquisa a respeito da gestão social, analisaram-se as características psicométricas e observou-se que apenas uma dimensão emergiu, com variância extraída de 59,4\% e Alpha de Cronbach de 0,76, demonstrando uma boa adequação, conforme pode se observar na Tabela 3 . assim, a indicação de que os estudantes consideram a formação prática em gestão social algo realmente importante. Adicionalmente, os desvios-padrão ficaram todos abaixo de um, e foram menores que os desvios das variáveis do primeiro fator. A indicação é, portanto, que os estudantes consideram a formação
Em relação às médias, todos os itens apresentaram indicadores entre intermediários e elevados, com os desvios em nível relativamente baixo, indicando uma certa concordância entre os respondentes. Éinteressante notar que o item o qual obteve a maior média $(3,73)$ 
foi o que demonstrava o interesse do respondente em participar de projetos sociais, enquanto os dois itens que tiveram as menores médias — 'probabilidade de fazer uma pós-graduação em gestão social’ $(2,61)$ e 'probabilidade de trabalhar como gestor social' $(2,96)$ — foram itens que acenavam com a possibilidade real de desenvolver uma carreira nesse sentido. Isso pode demonstrar que os alunos ainda encaram projetos sociais como algo dos quais se deve participar mais pela vontade de ajudar o outro ou por esses projetos serem bem vistos pela sociedade do que como uma real opção de carreira.

\subsubsection{Principais resultados encontrados em relação à Gestão Social}

Em uma análise dos três fatores integrados (os dois que emergiram da escala BERSI e o de 'intenções futuras'), percebe-se que:

Na medida agregada relativa à 'importância da formação na área' de gestão social, a média geral ficou em um nível intermediário $(3,88)$, considerando que a escala foi de 1 a 5 . A análise por gênero indicou, por outro lado, que há uma percepção de necessidade maior da parte das mulheres, inclusive com uma média que ficou já em um nível elevado $(4,09)$, ao passo que a média dos homens permaneceu em um nível moderado $(3,69)$.

Na medida agregada do fator, a 'importância do conhecimento prático’ em gestão social, as médias geral e por grupo foram todas elevadas (4,27 - geral; 4,17 - homens; 4,39 - mulheres), porém ainda assim a média das mulheres foi estatisticamente mais elevada que a dos homens.

No fator que congrega as 'intenções futuras', houve uma média moderada $(3,13)$, principalmente quando comparada aos resultados dos outros dois fatores anteriormente comentados. Aqui foi mais pronunciada a diferença entre gêneros, e a média das mulheres ficou em um nível moderado $(3,36)$, ao passo que a média dos homens ficou em nível baixo $(2,93)$.

Em todas as verificações, os valores dos desvios-padrão foram sempre baixos, indicando que, nas medidas agregadas, as percepções e as intenções são sempre muito convergentes entre os respondentes da amostra, independentemente do gênero dos estudantes.

Os resultados do estudo trazem algumas informações que os autores consideram relevantes, principalmente com relação aos estudos da área de gestão social nos cursos de Administração. Sabese, contudo, que o campo da gestão social pode ser considerado ainda em formação, a despeito de já ter seu elenco de atividades de educação e de pesquisa. Adicionalmente, o papel dos cursos de Administração, nesse campo, parece ainda incerto. A perspectiva da multidisciplinaridade parece estar atendendo adequadamente às demandas atuais.

\subsection{Análises do Construto na Gestão Ambiental}

Assim como na seção anterior, aqui serão apresentados os resultados descritivos e psicométricos da Escala BERSI e dos itens relativos às 'intenções futuras', agora em relação à Gestão Ambiental.

\subsubsection{Análises dos construtos da escala BERSI na Gestão Ambiental}

Na pesquisa a respeito da gestão ambiental, os dez itens da escala BERSI foram submetidos, inicialmente, a uma análise da estrutura fatorial, pelo método dos componentes principais, e com rotação varimax.

Conforme pode ser verificado na Tabela 4 - na qual constam, além dos escores fatoriais, a média e o desvio-padrão de cada uma das variáveis —, no primeiro fator estão sete variáveis, com variância extraída de 43,7\% e Alpha de Cronbach de 0,83. Analisando-se as sete variáveis, fica evidente a ênfase na 'importância da formação na área' de gestão ambiental. O segundo fator, por seu turno, contém três variáveis, com variância extraída de 11,1\% e Alpha de 0,67 . Essas três variáveis explicitam a 'importância do conhecimento prático’ em gestão ambiental. 
Importância Percebida e Intenções de Envolvimento com a Gestão Social e a Ambiental: uma análise comparativa junto a estudantes de curso de administração

Tabela 4 - Medidas das variáveis da escala BERSI para Gestão Ambiental

\begin{tabular}{l|c|c|c|c}
\hline \multicolumn{1}{c|}{ VARIÁVEIS } & \multicolumn{2}{|c|}{ FATORES $^{1}$} & \multirow{2}{*}{ Média } & \multirow{2}{*}{ Desvio } \\
\cline { 2 - 3 } $\begin{array}{l}\text { Cursos de Administração deveriam avaliar nos alunos conhecimentos sobre } \\
\text { responsabilidade ambiental }\end{array}$ & 0,810 & - & 3,94 & 1,00 \\
\hline $\begin{array}{l}\text { Cursos de Administração deveriam incluir tópicos nas várias disciplinas sobre } \\
\text { responsabilidade ambiental }\end{array}$ & 0,710 & - & 4,18 & 1,03 \\
\hline $\begin{array}{l}\text { Uma boa formação em Administração passa pela formação em gestão } \\
\text { ambiental }\end{array}$ & 0,693 & - & 4,00 & 1,03 \\
\hline $\begin{array}{l}\text { Cursos de Administração deveriam incluir no currículo conteúdos/disciplinas } \\
\text { sobre gestão ambiental }\end{array}$ & 0,687 & - & 4,43 & 0,79 \\
$\begin{array}{l}\text { Cursos de Administração deveriam preparar estudantes para serem líderes de } \\
\text { projetos ambientais }\end{array}$ & 0,626 & - & 3,94 & 1,00 \\
\hline $\begin{array}{l}\text { Cursos de Administração deveriam envolver os estudantes em assuntos } \\
\text { ambientais }\end{array}$ & 0,578 & - & 4,45 & 0,74 \\
\hline $\begin{array}{l}\text { O aprendizado sobre gestão ambiental é um assunto de grande importância para } \\
\text { a formação em Administração }\end{array}$ & 0,505 & - & 4,49 & 0,77 \\
\hline $\begin{array}{l}\text { Escolas de Administração deveriam oferecer oportunidades para que os } \\
\text { estudantes aumentem sua compreensão sobre gestão ambiental }\end{array}$ & - & 0,854 & 4,69 & 0,56 \\
\hline $\begin{array}{l}\text { Escolas de Administração deveriam incentivar estudantes para se envolverem } \\
\text { em projetos ambientais }\end{array}$ & - & 0,842 & 4,65 & 0,61 \\
\hline $\begin{array}{l}\text { Graduandos em Administração devem saber como resolver problemas de } \\
\text { gestão ambiental }\end{array}$ & - & 0,445 & 4,43 & 0,72 \\
\hline
\end{tabular}

${ }^{1}$ Expostos somente valores de escores acima de 0,$5 ;{ }^{2}$ Variância extraída - 43,7\%, Alpha (de Cronbach) - 0,83; ${ }^{3}$ Variância extraída - 11,1\%, Alpha - 0,67;

Fonte: dados da pesquisa.

As análises das médias dos dois fatores definidos indicam o seguinte: para o fator 'importância da formação na área' de gestão ambiental, as médias foram acima de 4 em quatro das sete variáveis. Esses valores podem ser considerados elevados, tendo-se em vista que as escalas foram de 1 a 5 . Já as outras três variáveis ficaram com média em torno de 4 , o que, apesar de ser um pouco abaixo das demais, ainda indicam um nível de concordância elevado com as afirmações. Os desvios das variáveis dos construtos podem ser considerados baixos, o que indica uma boa convergência de opiniões. Avaliando-se os resultados em conjunto para as sete variáveis, a média final foi de 4,24 e o desvio-padrão de 0,65. Esses dados indicam que os estudantes atribuem grande importância para a formação em gestão ambiental.

Analisando o segundo fator, que retrata a 'importância do conhecimento prático' em gestão ambiental, observa-se que as médias foram também bastante elevadas e que, nas três, os desvios foram muito baixos, comparativamente às variáveis do outro fator.

Fonte: dados da pesquisa.
A média geral do fator foi 4,59, enquanto o desviopadrão foi 0,49 , o que indica que, para esse fator, a média geral foi mais elevada que a do fator anterior, apontando, assim, um elevado grau de importância do conhecimento prático da gestão ambiental, além do fato de que as posições dos estudantes são, em geral, mais convergentes.

\subsubsection{Análises das 'intenções futuras'de envolvimento com a Gestão Ambiental}

$\mathrm{Na}$ análise dos itens referente às 'intenções futuras' de envolvimento, com a respeito à gestão ambiental, analisou-se as características psicométricas e observou-se que apenas uma dimensão emergiu, com variância extraída de $72,8 \%$ e Alpha de Cronbach de 0,88 , demonstrando uma ótima adequação, conforme pode se observar na Tabela 5.

Tabela 5 - Medidas das variáveis de intenções futuras em relação à Gestão Ambiental

\begin{tabular}{l|c|c|c}
\hline \multicolumn{1}{c|}{ VARIÁVEIS } & FATOR $^{1}$ & MÉDIA & DESVIO \\
\hline Probabilidade de fazer cursos diversos na área de gestão ambiental & 0,850 & 3,41 & 1,00 \\
\hline Probabilidade de me envolver em projetos ambientais & 0,804 & 3,64 & 0,93 \\
\hline Probabilidade de fazer uma pós-graduação em gestão ambiental & 0,882 & 2,87 & 1,12 \\
\hline Probabilidade de trabalhar como gestor ambiental & 0,874 & 3,01 & 1,03 \\
\hline
\end{tabular}

Probabilidade de trabalhar como gestor ambiental

'Variância extraída - 72,8\%, Alpha (de Cronbach) - 0,88. 
Em relação às médias, todos os itens apresentaram indicadores entre intermediários e elevados, com os desvios em nível relativamente baixo, indicando uma certa concordância entre os respondentes. É interessante notar que, da mesma forma que na pesquisa em relação à gestão social, o item que obteve a maior média $(3,64)$ foi o que demonstrava o interesse do respondente em participar de projetos na área, enquanto os dois itens que tiveram as menores médias - 'probabilidade de fazer uma pós-graduação em gestão ambiental' $(2,87)$ e 'probabilidade de trabalhar como gestor ambiental' $(3,01)$ - foram itens que acenavam com a possibilidade real de desenvolver uma carreira na área. Da mesma forma, acreditase que isso demonstra que os alunos ainda encaram a área ambiental mais como algo importante para a sociedade do que como uma opção de carreira a ser considerada.

\subsubsection{Principais resultados encontrados em relação à} Gestão Ambiental

Considerando os resultados para os três construtos (os dois que emergiram da escala BERSI e o de 'intenções futuras') acima definidos, bem como as médias definidas para as entradas de cada construto (composta pela média dos escores de cada variável componente), optou-se por avaliar os resultados levando em conta as variáveis categóricas da pesquisa. Para tanto, foram extraídas as médias e os desvios dos construtos em cada categoria das variáveis, enquanto as diferenças foram julgadas por meio da significância estatística da medida F, dentro da Análise de Variância (ANOVA). Os principais resultados encontrados estão comentados a seguir:

Nas variáveis de caracterização dos estudantes, o resultado mais interessante foi em relação à natureza da instituição. Nesse caso, verificaramse diferenças significativas nas três dimensões, tendo-se observado que os estudantes de instituições públicas diferem dos estudantes de escolas privadas, na medida em que aqueles atribuem maior 'importância da formação na área’ de gestão ambiental $(\mathrm{F}=9,128, \mathrm{p}<0,05)$, maior 'importância do conhecimento prático' em gestão ambiental $(F=11,906, p<0,05)$, e têm maiores 'intenções futuras' de envolvimento com a área $(\mathrm{F}=9,348, \mathrm{p}<0,05)$. Esse resultado surpreende, pois demarca uma diferença entre os estudantes dos dois tipos de instituições que não se justificaria a priori. A indicação é de que há um desafio para as instituições privadas na conscientização dos estudantes sobre o valor da área de gestão ambiental;

Também foi verificado que os estudantes que tiveram alguma experiência na área de gestão ambiental atribuíram maior relevância à 'importância ao conhecimento prático' na área $(\mathrm{F}=6,638, \mathrm{p}<0,05)$, maior ênfase em relação à 'importância da formação na área' $(\mathrm{F}=5,467$, $\mathrm{p}<0,05)$ e atestaram, também, maiores 'intenções futuras' de envolvimento com gestão ambiental $(\mathrm{F}=18,823, \mathrm{p}<0,001)$. A indicação aqui é de que caso as instituições desejem manter a atenção e o interesse dos estudantes, além de estimular seu envolvimento futuro, é necessário que elas os envolvam em projetos ambientais;

Em relação às variáveis demográficas, praticamentenão houve diferenças nas percepções e nas intenções, a não ser na dimensão 'intenções futuras", $(\mathrm{F}=3,287, \mathrm{p}<0,05)$ em relação ao estado civil, em que se verificou que os casados apresentaram a maior média, indicando um maior interesse em se envolver com o assunto.

\subsection{Comparativo da Escala Bersi nas Duas Pesquisas}

Observando a Tabela 6, comparativamente não houve grandes diferenças entre as médias encontradas para os construtos envolvendo a 'importância da formação na área' e a 'importância do conhecimento prático' em gestões social e ambiental no curso de Administração.

Mesmo considerando as diferenças pequenas, todas as médias relacionadas à gestão ambiental foram maiores do que em relação à gestão social, o que pode demonstrar uma atribuição de maior importância para gestão ambiental do que para a social perante os estudantes. 
Importância Percebida e Intenções de Envolvimento com a Gestão Social e a Ambiental: uma análise comparativa junto a estudantes de curso de administração

Tabela 6 - Comparativo escala BERSI - Gestão Ambiental x Gestão Social

\begin{tabular}{|c|c|c|c|c|}
\hline \multirow{3}{*}{$\begin{array}{l}\text { Variáveis } \\
\begin{array}{l}\text { 1. Cursos de Administração deveriam avaliar nos alunos conhecimentos sobre } \\
\text { responsabilidade social/ambiental }\end{array}\end{array}$} & \multicolumn{4}{|c|}{ Média / Desvio } \\
\hline & \multicolumn{2}{|c|}{ Gestão Social $^{1}$} & \multicolumn{2}{|c|}{$\begin{array}{c}\text { Gestão } \\
\text { Ambiental }^{2}\end{array}$} \\
\hline & 3,64 & 1,01 & 3,94 & 1,00 \\
\hline $\begin{array}{l}\text { 2. Cursos de Administração deveriam incluir tópicos nas várias disciplinas sobre } \\
\text { responsabilidade social/ambiental }\end{array}$ & 4,01 & 0,95 & 4,18 & 1,03 \\
\hline 3. Uma boa formação em Administração passa pela formação em gestão social/ambiental & 3,83 & 0,98 & 4,00 & 1,03 \\
\hline $\begin{array}{l}\text { 4. Cursos de Administração deveriam incluir no currículo conteúdos/disciplinas sobre } \\
\text { gestão social/ambiental }\end{array}$ & 4,10 & 1,00 & 4,43 & 0,79 \\
\hline $\begin{array}{l}\text { 5. Cursos de Administração deveriam preparar estudantes para serem líderes de projetos } \\
\text { sociais/ambientais }\end{array}$ & 3,80 & 0,94 & 3,94 & 1,00 \\
\hline $\begin{array}{l}\text { 6. Cursos de Administração deveriam envolver os estudantes em assuntos sociais/ } \\
\text { ambientais }\end{array}$ & 4,13 & 0,94 & 4,45 & 0,74 \\
\hline $\begin{array}{l}\text { 7. O aprendizado sobre gestão social/ambiental é um assunto de grande importância para a } \\
\text { formação em Administração }\end{array}$ & 4,14 & 0,87 & 4,49 & 0,77 \\
\hline $\begin{array}{l}\text { 8. Escolas de Administração deveriam oferecer oportunidades para que os estudantes } \\
\text { aumentem sua compreensão sobre gestão social/ambiental }\end{array}$ & 4,42 & 0,86 & 4,69 & 0,56 \\
\hline $\begin{array}{l}\text { 9. Escolas de Administração deveriam incentivar estudantes para se envolverem em } \\
\text { projetos sociais/ambientais }\end{array}$ & 4,36 & 0,97 & 4,65 & 0,61 \\
\hline $\begin{array}{l}\text { 10. Graduandos em Administração devem saber como resolver problemas de gestão social/ } \\
\text { ambiental }\end{array}$ & 4,30 & 0,84 & 4,43 & 0,72 \\
\hline
\end{tabular}

'Variáveis do construto 'importância da formação na área’: 1, 2, 3, 4 e 5, Variáveis do construto 'importância do conhecimento prático’: 6, 7, 8,9 e $10 ;{ }^{2}$ Variáveis do construto 'importância da formação na área': 1, 2, 3, 4, 5, 6 e 7, Variáveis do construto 'importância do conhecimento prático': 8,9 e 10 ;

Fonte: dados da pesquisa.

Na divisão dos construtos em dois construtos, as variáveis " 6 . Cursos de Administração deveriam envolver os estudantes em assuntos sociais/ambientais' e '7. O aprendizado sobre gestão social/ambiental é um assunto de grande importância para a formação em Administração' estiveram relacionadas à dimensão 'importância do conhecimento prático’ na pesquisa sobre gestão social. Na pesquisa sobre gestão ambiental, diferentemente, essas variáveis se adequaram melhor à dimensão 'importância da formação na área'.

Exploratoriamente, esse fato pode indicar uma percepção de maior importância de formação teórica para a gestão social do que a gestão ambiental. Ou seja, os alunos acham importante obter mais formação em gestão social, mas desejam por em prática mais a gestão ambiental.

\subsection{Esacla de Intenções Futuras - Comparativo entre estudos}

Com relação às quatro variáveis sobre as 'intenções futuras na área', também foram extraídas as médias e os desvios-padrão gerais por variável, tanto para os respondentes de gestão social quanto para os de gestão ambiental. Os resultados podem ser observados na Tabela 7.

Tabela 7 - Intenções futuras em relação à Gestão Social e à Gestão Ambiental

\begin{tabular}{l|c|c}
\hline \multirow{2}{*}{ Variáveis } & \multicolumn{2}{|c}{$\begin{array}{c}\text { Média } \\
\text { (Desvio) }\end{array}$} \\
\cline { 2 - 3 } & Gestão Social & Gestão Ambiental \\
\hline \multirow{2}{*}{ Probabilidade de fazer cursos diversos na área } & 3,23 & 3,41 \\
& $(0,80)$ & $(1,01)$ \\
\hline \multirow{2}{*}{ Probabilidade de me envolver em projetos na área } & 3,73 & 3,64 \\
& $(0,85)$ & $(0,93)$ \\
\hline \multirow{2}{*}{ Probabilidade de fazer uma pós-graduação na área } & 2,61 & 2,87 \\
& $(0,96)$ & $(1,12)$ \\
\hline \multirow{2}{*}{ Probabilidade de trabalhar como gestor na área } & 2,96 & 3,01 \\
& $(0,96)$ & $(1,03)$ \\
\hline \multirow{2}{*}{ Escore geral para intenções de envolvimento } & 3,13 & 3,23 \\
& $(0,68)$ & $(0,87)$ \\
\hline
\end{tabular}

Fonte: dados da pesquisa.

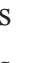


de gestão ambiental apresentando maior média $(3,41)$ do que os de gestão social $(3,23)$; e a 'probabilidade de fazer uma pós-graduação na área', novamente com os respondentes de gestão ambiental demonstrando ser os mais interessados, média 2,87 , do que os de gestão social, média 2,61. Já a menor diferença entre as médias das áreas se deu na variável 'probabilidade de trabalhar como gestor na área'.

De todas as médias, a única variável que esteve mais alta em gestão social do que em gestão ambiental foi a da variável ' probabilidade de me envolver em projetos na área', e foi essa também a maior de todas as médias $(3,73)$ de intenções futuras em relação à gestão social e à ambiental. E a menor de todas as médias também foi em relação à gestão social, e foi encontrada na variável 'probabilidade de fazer uma pós-graduação na área'.

Em relação a 'intenções futuras', o escore geral foi maior para a gestão ambiental $(3,23)$, o que indica maior interesse dos alunos em manterem envolvimento futuro com a área ambiental do que com a social. Ademais, os valores dos desvios, que foram também de nível baixo, indicam que essa posição é bastante convergente para ambas as amostras.

\section{CONSIDERAÇÕES FINAIS}

Este estudo foi desenvolvido para gerar e oferecer informações relevantes para o aperfeiçoamento da formação em Administração. Acredita-se que pode ser de real valor para que gestores de cursos e de instituições de ensino com cursos na área direcionem mais consistentemente os planos de formação para um campo que pretenda oferecer uma grande demanda de profissionais de Administração no futuro. Os resultados encontrados demonstram a necessidade de esforços para a realização de atividades voltadas para a Educação Ambiental e a Social. Devem ser levados em consideração os resultados apontados pelas análises realizadas: (1) os estudantes atribuem uma maior importância, no geral, para a gestão ambiental do que para a social; (2) eles atribuem uma maior importância teórica para a gestão social; (3) esses posicionamentos são influenciados, especialmente, pelo tipo de instituição e pela experiência na área na gestão ambiental, enquanto na gestão social são influenciados pelo gênero (homens e mulheres). Os resultados tendem a convergir pela necessidade de colocar em prática a proposta de Educação para o Desenvolvimento Sustentável, conforme apontado por Barbieri e Silva (2011), bem como para os resultados preliminares encontrados por Oliveira, Oliveira e Costa (2008), juntamente com professores, sobre a área de gestão ambiental, visando uma melhor formatação das técnicas de ensino.

Portanto, acredita-se que a abordagem desenvolvida seja do interesse de professores e de autores de materiais didáticos da área de gestão, que têm informações para embasar uma formatação mais consistente dos conteúdos, com base na agregação de tópicos sobre gestões ambiental e social nas disciplinas e em materiais como livros e apostilas. Adicionalmente, os resultados juntam-se àqueles de outros estudos (JABBOUR, SANTOS, BARBIERI, 2008; SCHOMMER et al., 2008), acreditando-se que, tudo isso, trará contribuições para novas pesquisas sobre o tema.

Os resultados foram, por outro lado, limitados, uma vez que a amostra foi restrita às instituições localizadas na região Nordeste do País, além do fato de a amostragem ter sido baseada em acessibilidade e conveniência. Seria relevante uma replicação desse estudo em outros estados e regiões brasileiras, de preferência com métodos de amostragem mais rigorosos, com o intuito, inclusive, de se chegar a uma validação mais precisa sobre a dimensão fatorial da escala BERSI, a qual nesse trabalho teve duas configurações distintas. O estudo também foi restrito a três construtos principais e deixou de abordar outras possibilidades. Recomenda-se, portanto, que outros tópicos associados ao tema gestão ambiental e gestão social sejam inseridos, tais como ética, voluntariado, responsabilidade social, para citar alguns.

Outros trabalhos poderão investigar o posicionamento de professores e de empresários sobre como deve ser o processo de formação do futuro administrador com relação a aspectos sociais e ambientais. Daí poderão ser comparados com os resultados aqui alcançados, na busca de uma convergência entre formação e aplicação prática dos 
Importância Percebida e Intenções de Envolvimento com a Gestão Social e a Ambiental: uma análise comparativa junto a estudantes de curso de administração

conhecimentos acadêmicos nas duas áreas.

\section{REFERÊNCIAS}

ABNT - ASSOCIAÇÃO BRASILEIRA DE NORMAS TÉCNICAS. NBR ISO 14001: Sistema da Gestão

Ambiental - Requisitos com orientação para uso. Rio de Janeiro, ABNT, 2004.

BAGOZZI, R. P.; EDWARDS, J. R. A general approach for representing constructs in organizational research.

Organizational Research Methods, v. 1, n ${ }^{\circ}$ 1, p. 45-87, 1998.

BARBIERI, J. C. Gestão ambiental empresarial: conceitos, modelos e instrumentos. São Paulo: Saraiva, 2004.

; SILVA, D. Desenvolvimento sustentável e educação ambiental: uma trajetória comum com muitos desafios. Revista de Administração da Mackenzie, v. 12, $\mathrm{n}^{\circ}$ 3, p. 51-82, maio/jun., 2011.

BRASIL. Lei No 9.795, de 27 de abril de 1999. Dispõe sobre a educação ambiental, institui a Política Nacional de Educação Ambiental e dá outras providências. Diário Oficial da União, Brasília, DF, 28 de abril de 1999. Disponível em:

$<$ http://www.planalto.gov.br/CCIVIL/LEIS/L9795.htm>. Acesso em: 5.mar.2008.

CAPRA, F (Org.). Alfabetização ecológica: a educação das crianças para um mundo sustentável. São Paulo: Cultrix, 2007.

ESTY, D. C.; WINSTON, A. S. Green to gold: how smart companies use environmental strategy to innovate, create value, and build competitive advantage. New Haven, CT and London: Yale University Press, 2006.

FRANÇA FILHO, G. C. Definindo gestão social. In: SILVA JÚNIOR, J. T.; MASIH, R. T.; CANÇADO, A.C.; SCHOMMER, P. C. (Orgs.). Gestão social: práticas em debate, teorias em construção. Fortaleza: Imprensa Universitária UFC, 2008, v. 1. 248 p.

HAIR, J. F.; ANDERSON, R. E.; TATHAM, R. L.; BLACK, W. C. Análise multivariada de dados. 5. ed. Porto Alegre: Bookman, 2005.

INSTITUTO AKATU. Centro de referência Akatu pelo consumo consciente. São Paulo: Instituto Akatu, 2009. Disponível em: < http://centro.akatu.org.br/cr/index.jsp>. Acesso em: 25.fev.2009.
INSTITUTO ETHOS. Aprendendo a lição de Chaco Canyon: do desenvolvimento sustentável a uma vida saudável. São Paulo: Instituto Ethos, 2005a.

. O compromisso das empresas com

o meio ambiente. São Paulo: Instituto Ethos, 2005b.

JABBOUR, C. J. C.; SANTOS, F. C. A.; BARBIERI, J.

C. Gestão Ambiental Empresarial: um levantamento da produção científica brasileira divulgada em periódicos da área de Administração entre 1996 e 2005. Revista de Administração Contemporânea, v. 12, nº 3, p. 689-715, ul./set., 2008

LASH, J.; WELLINGTON, F. Competitive advantage on a warming planet. Harvad Business Review, March, 2007.

MALHOTRA, N. K. Marketing research: an applied orientation. 3 ed. New Jersey: Prentice-Hall, 1999.

MELO NETO, F. P.; BRENNAD, J. M. Empresas socialmente sustentáveis: o novo desafio da gestão moderna. Rio de Janeiro: Qualitymark, 2004.

MINISTÉRIO DA EDUCAÇÃO. Sinopses estatísticas da educação superior - Graduação. Brasília, DF, 2009.

NASCIMENTO, L. F. Quando a gestão social e a gestão ambiental se encontram. In: Encontro Anual da Associação Nacional dos Cursos de Pós-Graduação em Administração, 31. Anais eletrônicos... Rio de Janeiro: ANPAD, 2007.

; LEMOS, A. D. C.; MELLO, M. C.

A. Gestão socioambiental estratégica. Porto Alegre: Bookman, 2008.

OLIVEIRA, L. G. L.; OLIVEIRA; D. M.; COSTA, F. J. A gestão ambiental nos cursos de administração: uma análise da perspectiva dos professores. Revista de Administração da UFSM, v. 3, nº 2, p. 205-218, maio/ago., 2010.

REIGOTA, M. O que é educação ambiental? São Paulo: Brasiliense, 1994.

RIGONAT, M. C. Hacia una educación ambiental anclada en el local. Revista Gestão em Ação. Salvador, v. 5, nº 2, p. 127-144, Jul./Dez., 2002.

SCHOMMER, P. C.; FRANÇA FILHO, G. C. Gestão social e aprendizagem em comunidades de prática: interações conceituais e possíveis decorrências em processos de formação. In: SILVA JÚNIOR, J. T.; MASIH, R. T.; CANÇADO, A.C.; SCHOMMER, P. C. (Orgs.). Gestão social: práticas em debate, teorias em construção. Fortaleza: Imprensa Universitária UFC, 2008, v. 1, 248 p. 
Importância Percebida e Intenções de Envolvimento com a Gestão Social e a Ambiental: uma análise comparativa junto a estudantes de curso de administração

; RAMOS, R. R.; MEDEIROS, A. C.;

VIANA, T. A. Articulando diferentes metodologias de aprendizagem no ensino de gestão social na graduação: uma proposta do curso de administração da UFC - Campus Cariri. In: CANÇADO, A. C.; SILVA JÚNIOR, J. T.; SCHOMMER, P. C.; RIGO, A. S. (Orgs.). Os desafios da formação em gestão social. Palmas-TO: Provisão, 2008, v. 2. $445 \mathrm{p}$.

SILVA, L. M. T. da; SILVA, M. P. da; ENDERS, W. T. Gestão ambiental e desempenho organizacional: um estudo de suas relações no setor hoteleiro. Encontro Anual da Associação Nacional dos Cursos de Pós-Graduação em Administração. 30. Anais eletrônicos... Salvador: ANPAD, 2006.

SILVA FILHO, J. C. L. Socioambiental: o perigo da diluição de dois conceitos. Gestão. Org. v. 5, n 2, p. 199-209, maio/ago., 2007.

SLEEPER, B. J.; SCHNEIDER, K. C.; WEBER, P. S.; WEBER, J. E. Scale and study of student attitudes toward business education's role in addressing social issues. Journal of Business Ethics, $\mathrm{n}^{\circ}$ 68, p. 381-391, Springer 2006.

TENÓRIO, F. G. Um espectro ronda o terceiro setor, o espectro do mercado: ensaios sobre a gestão social. 2 ed. Ijuí: Editora Unijuí, 2004.

(Re)visitando o conceito de gestão social. In: SILVA JÚNIOR, J. T.; MASIH, R. T.; CANÇADO, A. C.; SCHOMMER, P. C. (Orgs.). Gestão social: práticas em debate, teorias em construção. Fortaleza: Imprensa Universitária UFC, 2008, v. 1. 248 p. 